\title{
Cybernetic Solutions in Analytical Management of Company's Business Activity in Stable Growth Conditions
}

Submitted 21/08/19, 1st revision 22/09/19, 2nd revision 12/10/19, accepted 17/12/19

\author{
E.V. Kuznetsova, ${ }^{1}$ D.S. Teleev, ${ }^{2}$
}

\begin{abstract}
:
Purpose: The article is aimed at the formation of a new methodology of accounting and analytical management in business processes. The study of tasks, methods and techniques of cybernetics and refract them through the prism of algorithm of business process, gives the possibility for forecasting in stable economic growth conditions.

Design/Methodology/Approach: To realize the possibilities of analyzing and forecasting resources in a business process, it is important to define the "input resources", the information field of business processes, that is expressed in the idea of production, product characteristics data, output volume, generation of information on necessary "input resources" and possible" output resources", sales information, as well as methods of economic analysis such as marketing analysis, managerial analysis etc. and the accounts' forecasting.

Findings: To define the influence of the information field of a business process on its key indicators such as actual results, changed of human resources, acquisition, development and implementation of new technologies, there has been an accounting and analytical model developed. Its work is based on bookkeeping and economic analysis tools and a cybernetic feedback method.

Practical Implications: The results can be implemented to forecast the outcome at each stage of business process and further on for the organization of any type of activity and any form of ownership.

Originality/Value: The main contribution of this research is the generation of accounting and economic analysis tools with methods of cybernetics, which allows us to form a new scientific direction from a theoretical standpoint, and to manage business processes through the information field in practical terms.
\end{abstract}

Keywords: Business process, cybernetics, accounting and analytical management, account projectors, feedback, forecasting.

JEL code: $Q 01$.

Paper Type: Research article.

\footnotetext{
${ }^{1}$ Doctor of Science (Economics), Professor of the Department «Business Analysis and Forecasting» Rostov State University of Economics, Rostov-on-Don, kuev@mail.ru ${ }^{2}$ Graduate student of the Department «Business Analysis and Forecasting» Rostov State University of Economics, Rostov-on-Don, teleev2012@yandex.ru
} 


\section{Introduction}

The demand for managing business processes of organizations arises at various levels of both internal managerial staff and external respondents. In this regard, many methods are currently being proposed for implementing management processes. In this case, it is advisable to initially proceed from the depth of understanding of the business process as a phenomenon and identify the main key positions, by which, in our opinion, should be characterized each business process and which may become starting points in the organization of accounting and analytical management of business processes. These are the starting points of a business process:

1. The purpose of the business process.

2. The path of the business process.

3 . The result of the business process.

It should be remembered that each of these positions has an internal and external side, that is, what is necessary for business itself as an organization, and what economy, society, and the state need.

So, our guess is that the aim of the business process is to create value. There are internal and external values. Internal values are primarily organizational values that distinguish one business process from another. For example, the Shell Group campaign is for a long time notable for its commitment to business principles based on basic values: decency, honesty, respect for people, fostering trust, openness, teamwork, professionalism and pride. Shell states that its values "mean that we are proud of what we do give us clarity in making decisions, unite and motivate the staff, and allow society to evaluate our activities that go beyond just creating wealth" (Grant, 2011).

The external value in our opinion is creation of a certain unique product, technology, market grouping of new products, works, services. The second key position of the business process is the path that resides in the following facts:

1) improving the efficiency of resource exploitation (in terms of innovation);

2) the introduction of new technologies (in terms of scientific and technological progress);

3) making a profit (in terms of finances).

The efficiency of resource exploitation is one of the key qualitative indicators characterizing the innovative development of both the organization and society. Moreover, meantime the efficiency is understood not only as the process of using one or another resource, but also the effectiveness of the resource itself. The introduction of new technologies may be called the litmus test of participation or non-participation of the organization in the development of scientific and technological progress. There may be product release technology, sales technology, organizational technology etc. From the point of view of an enterprise, the introduction of a new technology allows us to 
be leaders in our industry and occupy a rightful place in macroeconomic processes. From the point of view of the enterprise external manifestation of technologies introductions, this is the development of scientific and technological progress. Each organization, as a unit of the economy, contributes (or does not contribute) to the development of scientific and technological progress, and technology is a key position. Especially valuable is the patenting of technologies, which, first, is the recognition (Grant, 2011) by the state of the technological achievements of the enterprise, second, makes the technology protected from raider capture, and third, it can be taken into account as an invisible asset (Polyakova et al., 2019; Thalassinos et al., 2009).

Quite a lot of questions are raised by the fact that profit is recognized as part of the company's path, a part of business process, but not its result. Profit for business is like breathing for life. Life is impossible without breathing, but it is not the aim of life. In the same way profit is important to the life of a company, but it is not the reason for its existence. From the point of view of a company, profit, being a financial result, serves as a source of own funds for reinvestment. The external significance of profit is expressed in the importance of a company as a taxpayer.

In our opinion, the result of a business process is fulfilling by the organization of its mission. The internal mission of a company we see in the formation and accumulation of ownership. Here is provided a rather broad understanding of property, which includes intellectual, social, and other types of capital. Also, one of the key indicators of the mission from the point of view of a company is the formation of high-tech property and assets - this makes the company attractive and gives possibilities to attract additional funds for development (Negimov et al., 2018).

Moreover, the fulfilment of the mission exactly forms the individuality of a company, its ideology. We mean, if just profit was taken as the result, as is often assumed, then all companies would be alike. We see individuality precisely in those organizations, which see the company's mission and future intentions as a result.

By themselves, neither the aim of profit maximization (or shareholder value), nor the values defining the behavior of companies by themselves play a big role in establishing policy. The starting point for strategy is some profound idea about the reasons of business existence. Jim Collins and Jerry Porras state, that basic values should be supplemented by a basic value, the most important reason for a company existence. The main aim of the Walt Disney Company is to make people happy, not to make movies or build theme parks. Core values and core purpose form the basic ideology of an organization, which "defines the timeless character of a company" and is "the glue that ensures the organization unity." The basic ideology forms the main element of a company's image, which is the core of its strategy. The basic ideology answers the question what this company is, but it does not reflect the direction the company goes in. Therefore, the second essential component of the vision is the opinion concerning the company's future development (if we use the terminology of Collins and Porras, 
the predicted future). This view of the future should be clearly drawn down. On the one hand, one can brightly describe future intentions. In this connection we recall the statement of Henry Ford: "I will build a motor car for the great mass of people ... But it will be so low in price that no man making a good salary will be unable to own one - and enjoy with his family the blessing of hours of pleasure in God's great open spaces... When I complete my plan, everyone will able to purchase this car-everyone will have it" (Grant, 2011).

\section{Cybernetic Solutions in Business Process Management}

The possible management decision may be an engineering approach, which is a certain stage in the accounting and analytical management system, since in present times, perhaps one of the main roles in organizing a business process and in its management is played by information that works the business process on a feedback principle, namely the information affects the business process, and the functioning business process changes information. Whereby, human resources are the primary data carrier, and technology is the technical data carrier.

However, there is another alternative approach to accounting management of a business process. Thoroughly, it is necessary to define and develop the science of managing these processes in the accounting and analytical direction. Cybernetics may become such a science.

Rumyantseva (2011) defines cybernetics as the science of managing all systems. The contribution of cybernetics to any control system consists, first, in the general principles of management. The principle of hierarchy, the principle of control, the principle of the necessary diversity between the object and subject of management, the principle of systemicity, the principle of control according to aims.

Volkova (2012) refers to translations of the term "cybernetics" from Greek (helmsman) into the Latin, French and Russian words "governor", another translation is the art of controlling a ship, the art of helmsman. Cybernetics is the term adopted to name "science of control in living organisms and machines" by Norbert Wiener (1948) and widely used in the middle of the 20th century. Wiener is justly called the father of cybernetics. His book "Cybernetics", first published in 1948, shocked many with the unexpected conclusions. "Cybernetic explosion" by Wiener was prepared in the process of knowledge building.

The convergence of the technical means used both in physiology and in automation is accompanied by a mutual exchange of the principles of constructing structural schemes, ideas of modelling, methods of analysis and synthesis of systems. During World War II, the USA Department of Research and Development gave priority to working on a long-term atomic bomb project, as well as solving the more urgent task of finding ways of destroying German bombers. While the main work on the creation of the atomic bomb was carried out in Los Alamos, the research on the methods of 
detecting, tracking and destroying aircraft was carried out mainly at MIT, where Wiener was responsible for developing the mathematical tool necessary to solve this problem. In collaboration with the young engineer Julian Bigelou, N. Wiener developed a general mathematical theory for predicting the best options for the future, based on incomplete information about the past.

This theory rebounded a revolutionary overthrow in the practice of creating communication tools and laid the basis for the modern statistical theory of communication and information. At that time (1940s), this theory immediately led to a significant improvement in the methods of tracking aircraft using radars and began to be successfully used for creation noise filtering devices for radios, telephones, and many other general-purpose devices. This work was carried out by N. Wiener at about the same time when, aside of him, Claude Shannon (1948) created his "mathematical theory of information transfer".

One of the most interesting aspects of the air defence problem was related to the creation of a feedback loop: the information from the radar screen was used for calculating the corrections, necessary for guidance of the weapon of destruction and increasing of guidance accuracy, and then the effectiveness of these corrections was tracked and displayed using the radar, thereupon this new information was used to clarify the aiming of the weapon at the target again, etc. If the calculations in this process were carried out automatically, such system worked as self-managed; if the calculations were not automated, the whole system, including the people acting in it, was also selfmanaged. The most important guess of N. Wiener was precisely that similar feedback tools are used in all types of purposeful activities, for example, in the case when we take an ordinary pencil from the table. In this case information is perceived mainly through observation and is permanently used to control our arm muscles till the moment the problem is successfully solved (Warner, 2001).

Demonstrating the fact that there is a fundamental similarity between the control mechanism used in various sciences, cybernetics was able to eliminate the long-standing philosophical contradiction between vitalism and the mechanism, according to which biological and mechanical systems used to have a fundamentally different nature. In fact, cybernetics in accordance with the philosophical position of N. Wiener, accepted a much wider classification of systems and thus showed its interdisciplinary nature. A useful criterion for the classification exercise is the idea of complexity, according to which the main interest of cybernetics is the study of complex (namely, so complex that they cannot be described in a specified and detailed form) and stochastic (as opposed to deterministic) systems. Typical examples of such systems are economics, human brain and a commercial company.

To study the control and information transfer mechanism in such systems, N. Wiener and his colleagues developed the concepts of feedback, homeostasis and the "black 
box". Each feedback loop implies the use of incoming information and output, moreover - and this is of paramount importance - the information at the input is affected by the output, for example, the heater power will determine the readings taken from the thermometer, which in its turn will affect turning on or turning off signal of the heater. Thus, goes on the continuous monitoring of the discrepancy between the desired and the real situation. If the control mechanism acts in the direction of reducing this discrepancy, such a feedback is called negative; if the feedback increases the discrepancy, it is called positive.

A classic biological example of homeostasis is blood temperature homeostasis, which allows you to keep your body temperature almost unchanged, despite the body moving from a cold to a warm room. Thereby, homeostat is a control instrument for maintaining certain variables within prescribed limits. So, a typical example of a homeostat is the steam pressure regulator created by $\mathrm{J}$. Watt in a steam locomotive, engineered for controlling its speed by different load values.

It is extremely important to understand that the output of the controlled variable beyond the desired limits (when the speed of the steam locomotive is too fast or too slow) intrinsically plays the role of back coupling (when the adequate closing or opening of the valves in the Watt's regulator occurs). In other words, if the mechanism itself is functioning, its feedback coupling will also work properly. This conclusion is of great importance, since it implies that the feedback coupling of the regulator will always reliably compensate not only for this type of response, but also any type of response. This particular property of control systems is usually called ultra-stability. Thus, the concept of "control" in cybernetics is not reduced to a naive idea of the forcing process but implies the realization of self-regulation.

Another important concept of cybernetics that has gained popularity in many other sciences is the "black box". As previously stated, cybernetics is mainly engaged in the study of control mechanisms and information transfer in complex stochastic systems. The concepts of feedback and homeostasis are used to study the process of controlling cybernetics; statistical information theory is used to analyze probabilistic characteristic systems; finally, the study the complexity of systems is carried out by using the concept of a black box. Representing the system as a black box, cybernetics automatically agree with the cognitive limitations of their understanding of the huge number of possible states, that are available to a complex system at any given time.

However, they admit the possibility of manipulating some input signals and observing some of the results of the system activity on output. If the output signals are continuously compared with the specific desired values, some system responses may be determined from the point of view of their influence on the input signals of the black box in order to keep the system in a "controllable status" (Warner, 2001). 
By developing the cybernetic direction, S. Beer became the successor of Wiener's ideas in the field of operations research and scientific management methods (Volkova and Emelyanova, 2012).

In "Cybernetics and Management", S. Beer explains the basic concepts of cybernetics. He affirms that cybernetic systems have three main properties. First, they are complex, probabilistic and self-regulating. Second, they are task-oriented, i.e. from an individual point of view each system is created for achieving a certain goal. Third, they are characterized by feedback and control, which determine the behavior of a goal-oriented system. Many systems, due to their extreme complexity, cannot be specifically defined. The behavior is studied by identifying the logical and statistical relationships existing between the input and output information - in this case the system is considered as a "black box".

S. Beer (Volkova and Emelyanova (2012) gets a link between cybernetics and information theory and the works of Claude Shannon. The effective system operation depends on its ability to glow, transmit and transform information. Information destroys multiplicity (complexity) and reducing of diversity is one of the main management tools. This process is not aimed at simplifying the system, but at making its behavior more predictable.

According to S. Beer (Volkova and Emelyanova, 2012), the main tool of a cybernetician, is the "model". Beer's models are logical cybernetic descriptions of systems. A change in the state of a system can be represented as a change in the logic of its actions. Thus, dynamic systems are described by models together with sets of rules for changing their state. The use of ORMS is carried out by mental logic regard of the model. S. Beer notes that the initial task appears along with the creation of a logical cybernetic description.

Models conceivably imply the necessity of comparison. According to S. Beer (Volkova and Emelyanova, 2012) a formal scientific process begins with a comparison of conceptual models. There are two types of conceptual models: the first is based on the idea of how "the system actually works", and the second resembles the first with the only difference that it creates a correspondence with the scientific idea of the ORMS specialist about "how really the situation works". Then the specialist assesses how far the behavior of one system illuminates the behaviour of another one; how the theories, currently supported by scientists within one area, may be transferred to another area; if the existing research and calculation methods are suitable for this task; if the upright conclusions for one system, will be rightful for another. Finally, the researcher finds out, by means of which methodology the correspondence may be considered as strictly confirmed.

B.I. Kuzin defines the role and place of cybernetics in the correlation of theory systems and organization theory as in Figure 1 (Volkova and Emelyanova, 2012). 
Figure 1. Correlation of theory of systems, theory of organizations and cybernetics

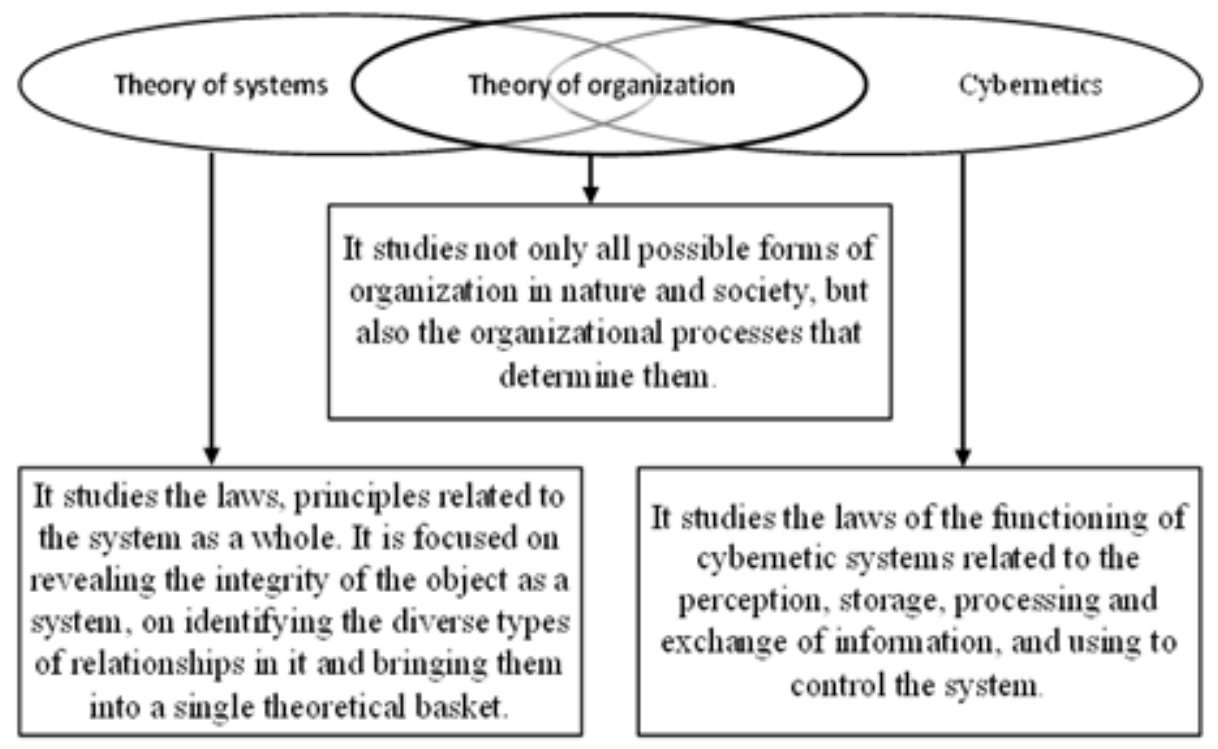

Cybernetics studies the laws of functioning of a special kind of systems that are called cybernetic and are associated with the concept of control, with the perception, storage and processing of information. Cybernetic systems are one of the varieties of the organizational whole and therefore are in the field of view of the general theory of organization and are used to generalize organizational experience. The general theory of systems deals with the laws and principles that apply to the system. It is focused on revealing the wholeness of the object as a system, on identifying the variety of types of connections in it and uniting them into a single theoretical picture. It is common between the theory of organization and the theory of systems. And the differences between them arise out of the origin of the terms of "organization" and "system". These terms are identical only in the part that concerns their entirety of origin.

The theory of organization is based on three main areas of scientific knowledge: mathematical, natural and social. This determines the connection between the theory of organization and other areas of scientific knowledge (Volkova and Emelyanova, 2012). The ideas of cybernetics are also used in various application areas - in biology (bio-cybernetics), medicine, etc. A spectrum of diverse theoretical and applied areas of cybernetics has developed. There are attempts to classify these areas.

For example, the academician A.I. Berg (Volkova and Emelyanova, 2012) proposed dividing all cybernetic researches into three main parts:

1. General, or theoretical, cybernetics, which deals with general mathematical models of control and is essentially a mathematical or physical-mathematical discipline. 
2. Technical cybernetics, the area of which is the technical realization of various complex objects, such as robotic realization, development of technical complexes and technical objects control systems.

3. Applied cybernetics that unites different applied areas of cybernetics - biological, medical, economic, military, agricultural, pedagogical, psychological, etc. (Volkova and Emelyanova, 2012)

The academician V.I. Danilov-Danilyan (2003) defines economical cybernetics as a system of theoretical principles that explain processing taking place in the national economy from the perspective of organized and informational changes in its structures, using as a methodological basis terms and concepts of automatic regulation theory, information of the theory of automatic regulation, information theory, cybernetics, computer science and other allied disciplines. Broadly defined the term of economic cybernetics, it includes the whole range of disciplines and scientific areas that define the application of mathematical methods and electronic computing in economics, management of organizational systems, economic data classification and processing and make organizational and economic decisions.

The main method of economical cybernetics is object modelling, which is used extremely widely, but at the same time, the modelling methodology usually remains within rather rigid boundaries of mechanical concepts. The model in the understanding, typical for economic cybernetics, is a kind of a "machine" that provides the conversion of the signal at the input to the signal at the output, but also, as a rule, is not indifferent to the method and nature of its functioning. Economical cybernetics is characterized by the construction of models that analyze previous proceeding and take into consideration its effectiveness in the realization of previous decisions. In other words, economic cybernetics models usually differ by adaptive features, learning ability, have the ability to reflect the adaptability of the simulated systems to environmental changes of their functioning and to transition according to the new values of its parameters to modified fairly stable mode (Danilov-Danilyan, 2003).

Thus, having researched the theoretical principles of cybernetics and the scope of its economic application, we can distinguish the main key terms:

- system;

- target;

- information;

- feedback;

- homeostasis;

- management;

- self-organization;

- input resources;

- output resources, etc. 
There is a direct connection of the manifestation of these economic categories in the organizations' business process in the context of our research. In our opinion, the business process is, of course, a system, namely, a complex object that represents some single whole. This is attested to by both, theoretical construction of the thesis research (the business process cycle, the business process "road map"), and an application example (the business process of automobile manufacture).

Management is a necessary element of the full functioning of the business process, both end-to-end and beginning-to end. Business process management is necessary at least in two aspect views: first, to maintain stability, that is, the ability to return to a state of economic equilibrium after the organization was withdrawn from it under the influence of internal and external factors; second, management, from the point of view of self-organization due to goal-setting, that is, the development of a leading enterprise (Polyakova et al., 2019).

Self-organization is a term that characterizes the ability of complex systems to reach a new level of development and, in particular, to increasingly display such properties as the ability to resist entropy processes and to develop anti-entropy (negentropy) tendencies, adapt to changing conditions, transforming its structure if necessary, and remain stable at this (Volkova and Emelyanova, 2012).

In our opinion, from the point of view of these two aspects, acts the process of homeostasis, that is, the ability of system to maintain the value of key variables within specified limits during interaction with the environment. This understanding refers to the first aspect, namely, to keeping a stable balance of the business process. However, there is no room for maneuver, for a "jerk." When it is necessary to maximize, not stabilize the business process, it makes sense to use the adaptability principles. The basis of self-organization and development of systems that allows you to adapt to changing conditions is a feedback. It may be positive and negative.

Negative feedback resists the tendency of output parameter change, that is, aimed at maintaining, stabilizing of the required parameter value (for example, stabilizing of the number of products, etc.). Positive feedback retains the trends of this or that parameter change in each system (this is used in modelling of developing systems) (Volkova and Emelyanova, 2012). The "input resources" and "output resources" indicators are key indicators of the "black box" model that is widely used in cybernetics (Figure 2) (Volkova and Emelyanova, 2012).

Having researched cybernetics' abilities, its application in the economic sphere, and basing on the "road map" of the business process, it becomes obvious that modelling the business process led us to the so-called "black box", with "input resources" and "output recourses". In this regard we proposed a scheme of implementation of analysis capabilities and forecasting of business process resources at the expense of its information field (Figure 3). 
Figure 2. The 'Black Box' model.

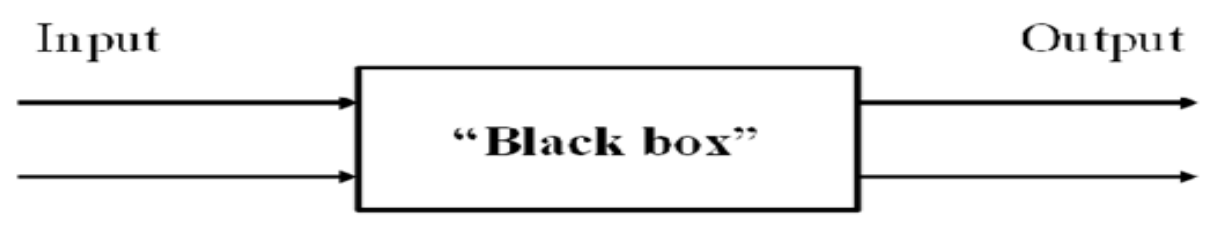

The functioning process itself, based on the cycle proposed above, is a specific field, namely, a field for generating information that appears at all stages of the business process cycle. Moreover, the principle of a feedback functioning takes part here. In other words, the process ceases to be omnidirectional: the available "input resources" are included in the functioning of the business process through the formation of production idea, the formation and utilization efficiency of various resources, the development and technology adoptions, sale of products, and then the sale and formation of "output recourses "in terms of certain ownership indicators.

However, the accounts and sections of the account plans are a kind of information accumulators. When we watch this process using the tools of cybernetics, the feedback effect allows us to form "input resources" and predict "output resources" due to the information field of the business process. In this case, the methods of economic analysis are applied. At the first stage of the business process cycle information about new products, their quality characteristics, and the required production volume is generated. This information is shaping by using marketing analysis techniques.

The formation of information about the required "input resources" is carried out by means of managerial analysis methods that allow us to determine the needs of the enterprise in material and labor resources, of basic assets. In this case it is necessary to consider not only the quantitative side of resources, but, first, the qualitative: conceptually new materials, high-tech equipment, the technologies and qualified staff that will make use of it. The information obtained in this way influences and forms the data, reflected on "input resources" accounts. Thus, there is a mutual feedback between incoming resources and the business process functionality, which is formed by means of information, the information field of the business process.

Mutual influence due to the feedback also occurs between the information field of the business process and the "output resources". Namely, there are actual and forecasted outgoing resources, that is, key indicators of ownership. We obtain actual values as a result of the business process's functioning, and forecast values due to forecasting tools, in particular, account projectors (the method of calculating the values of account projectors was proposed in the dissertation of Katerinin S.P. and registered in Rospatent (Patent and Trademarks Agency of Russia) as a computer program). And they, in turn, have an impact on the business process itself, indicate the need to change certain parameters of the business process. For example, the predicted magnitude of changes in human resources or the volume of technology creates information about 
the necessity of forming certain quantitative values and qualitative characteristics of these resources during the implementation of the business process.

Figure 3. Scheme of analysis capability implementation and business process resources forecasting at the expense of its information field

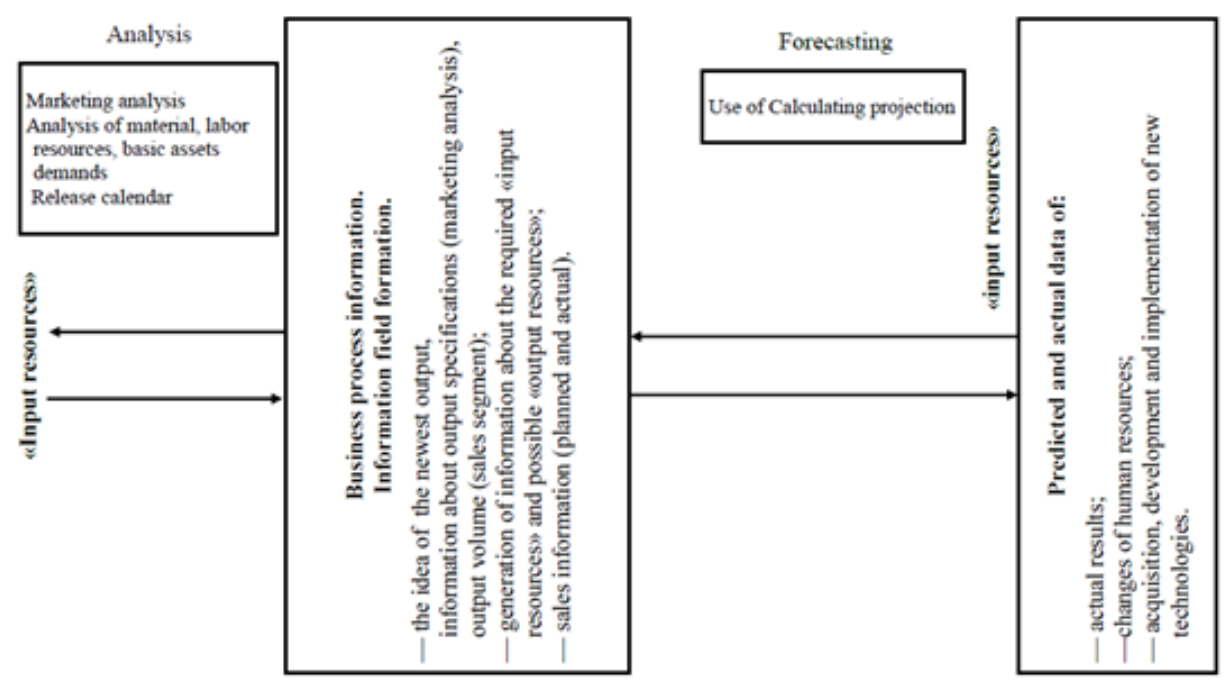

\section{Conclusion}

Thus, we have developed and proposed for use an engineering system of accounting and analytical management in business activities, which is based in its sequence on the "roadmap" of the business process. Information is generated on the accounts and sections of the accounts plans, in which we aggregated assets, liabilities, responsibilities to the level of mega-accounts, we also allocated accounts, which, in our opinion, play a decisive role in shaping the results of the business process functioning.

The "road map" stage, associated with the implementation of the business process, is represented by the cycle phases and at each of these phases the factors acting upon the change in ownership are identified. The influence of each factor is determined in the corresponding derivative balance record and its results are integrated into the general accounting and analytical system of business process management.

In total, it becomes possible to determine the change in assets, at the expense of human resources, technologies and property, among other things due to human and technological potential in terms of the business process cycle phases, on the one hand, and due to each factor by itself, on the other hand. According to the results of the implementation of the engineering system of accounting and analytical management of the 
business process, the company managers get a general change of assets and property, obtained by the results of management measures.

Thus, the capabilities of accounting tools (accounts and sections of plan accounts on where resources are reflected), of analysis methods (marketing analysis, managerial analysis etc.), of accounting procedures forecasting (projection accounts) and the principles of cybernetics, especially economic cybernetics, allow us to speak about the existence and development in the scientific direction of accounting and analytical cybernetics, and formulate the author's understanding of this direction. Accounting and analytical cybernetics is a scientific field that develops methods for managing economic processes by accumulating information on accounting records, transforming information through analytical and forecasting procedures, and modelling business process according to the information field.

\section{References:}

A Dictionary of Accounting. 2009. Oxford University press, fourth edition.

A Dictionary of Business Management. 2009. Oxford University press, fifth edition.

A Dictionary of Economics. 2010. Oxford University press, third edition.

A Dictionary of Finance and Banking. 2008. Oxford University press, fourth edition.

Danilov-Danilyan, V.I. 2003. The Encyclopedic Economic and Mathematical Dictionary. Moscow, Infra-M, 614.

Grant, R.M. 2011. Contemporary Strategy Analysis. Saint-Petersburg, Piter, 72-73.

Katerinin, S.P. 2016. Accounting and analytical system of management of innovative activity of the organization. Ph.D. thesis. Rostov-on-Don, RSUE.

Nagimov, A.R., Akhmetshin, E.M., Slanov, V.P., Shpakova, R.N., Solomonov, M.P., Il'yaschenko, D.P. 2018. Foresight technologies in the formation of a sustainable regional development strategy. European Research Studies Journal, 21(2), 741-752.

Polyakova, A.G., Loginov, M.P., Serebrennikova, A.I., Thalassinos, E.I. 2019. Design of a socio-economic processes monitoring system based on network analysis and big data. International Journal of Economics and Business Administration, 7(1), 130-139.

Rumyantseva, E.E. 2011. New Economic Encyclopaedia. Moscow, Infra-M, 227.

Shannon, C.E. 1948. A Mathematical Theory of Communication. Bell System Technical Journal, 27, 379-423.

Thalassinos, I.E., Hanias, P.M., Curtis, G.P. and Thalassinos, E.J. 2009. Chaos theory: Fore casting the freight rate of an oil tanker. International Journal of Computational Economics and Econometrics, 1(1), 76-88.

Usenko, L., Zenkina, I. 2016. Modern Trends and Issues of Corporate Reporting Data Disclosure on Organization Activities. Mediterranean Journal of Social Science, 3(7).

Volkova, V.N., Emelyanova, A.A. 2012. System Theory and Analysis in Business Management. Moscow, Finance and Statistics, 311.

Warner, N. 2001. Classics of Management. Saint-Petersburg, Piter, 212-213.

Wiener, N. 1948. Cybernetics: Or control and communication in the animal and the machine. Paris, Hermann and Cie \& Camb, MIT Press. 